\title{
A Coastal Model Supporting Urban Catchment Management
}

\author{
D. Strauss ${ }^{\mathrm{a}}$, A. Bordet ${ }^{\mathrm{ab}}$, and C. Buhr ${ }^{\mathrm{ab}}$ \\ ${ }^{a}$ Griffith Centre for Coastal Management, Griffith University, Gold Coast, Queensland, Australia \\ ${ }^{b}$ Enseirb-Matmeca, Bordeaux Polytechnic Institute (IPB), Bordeaux, France \\ Email:d.strauss@griffith.edu.au
}

\begin{abstract}
This paper presents outcomes from the development of hydrodynamic model of Tallebudgera Creek, a small coastal creek in South-East Queensland, Australia. The entrance to Tallebudgera creek is situated on a coast which is subject to highly variable wave energy, including swell events derived from occasional tropical cyclones. A prevailing longshore sediment transport rate of approximately 500,000 $\mathrm{m}^{3} \mathrm{yr}^{-1}$ is derived from an oblique wave approach due to the predominantly south-east wave direction. The entrance is subject to infilling by marine sands and is currently dredged annually to mitigate flooding impacts and to maintain water quality.

The model is calibrated with water level and discharge data and describes the flow behaviour for this welldefined hydrodynamic system with the inclusion of wave-current interaction at the entrance. The model was developed in order to simulate and to test the impact of a range of potential future management schemes for the creek, such as modifications to the entrance or changes to the present maintenance dredging regime.

The model was found to be sensitive to bed roughness at upstream locations more than at the downstream region. The presence of a weir-like structure upstream resulted in a modified tidal signal.
\end{abstract}

Keywords: Hydrodynamic model, Tallebudgera Creek, tidal inlet, dredging, sediment transport 


\section{INTRODUCTION}

Tallebudgera Creek is a small stream and tidal entrance located on the east coast of Australia at approximately $28^{\circ} 06^{\prime} \mathrm{S}$ and $153^{\circ} 27^{\prime}$ E. Tallebudgera Creek flows from its headwaters on the Springbrook Plateau (at 900 metres above mean sea level) down to the Pacific Ocean, a distance of approximately 30 kilometres. Precipitation over the catchment is the dominant source of the flow in Tallebudgera Creek; consequently the flow rate varies significantly throughout the year. Typically however, the mean flow of the lower reach is very weak with a peak velocity over a tidal cycle of $0.22 \mathrm{~ms}^{-1}$ recorded by DHI (2011).

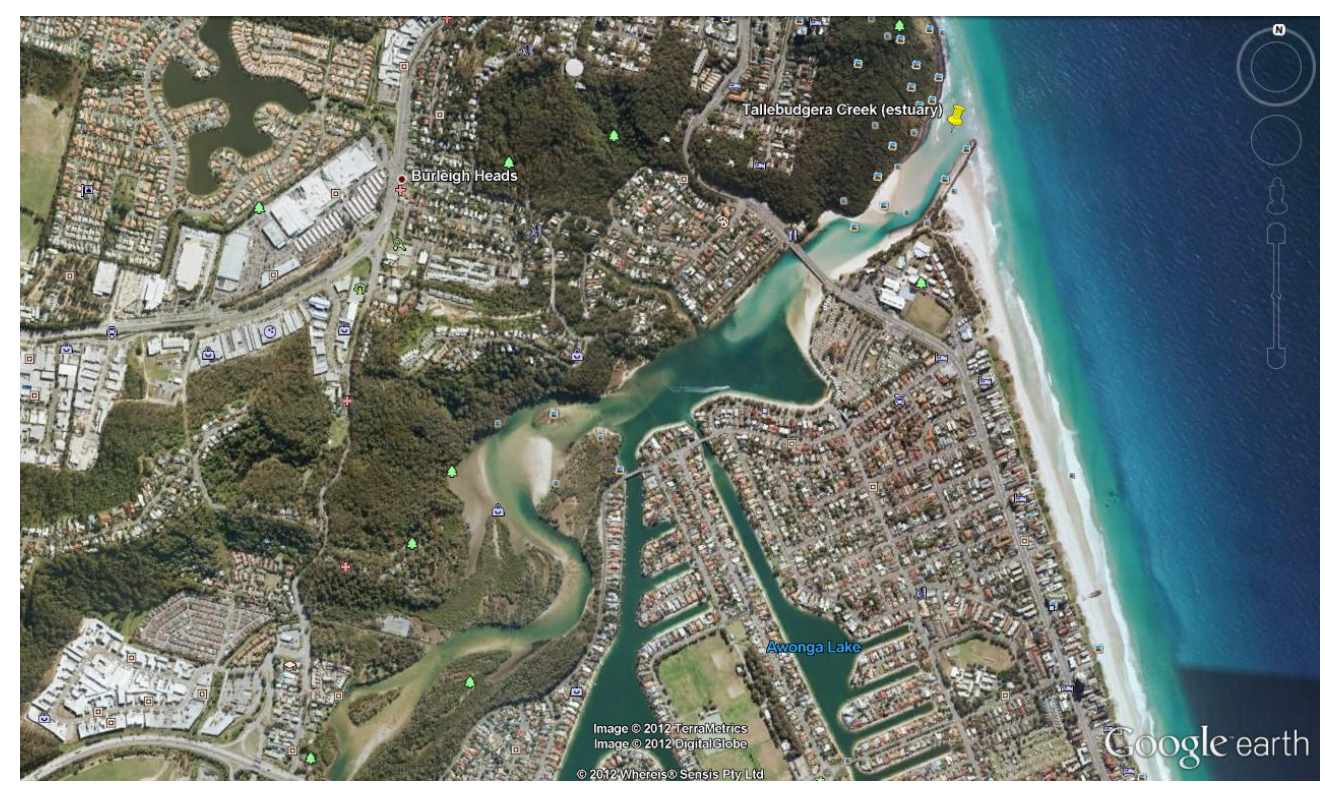

Figure 1. Lower reach of the Tallebudgera creek tidal inlet.

The open coast experiences a net northward littoral drift of approximately 500,000 $\mathrm{m}^{3} \mathrm{yr}^{-1}$ of fine sand with a median grain size of $0.2 \mathrm{~mm}$. The northward littoral drift results from the predominantly southeast swell direction of incidence; however wave climate can be highly variable in southeast Queensland. The tide is characterised as semi-diurnal with tidal amplitude of 0.8 to $2 \mathrm{~m}$ (MSQ, 2013). Considerable quantities of sand enter the estuary throughout the year and one of the principal management issues related to Tallebudgera Creek is the mitigation of impacts of flooding upstream due to closure by sand banks at the entrance. Those living in close proximity to the creek and connecting canals are particularly vulnerable to the impacts of flooding (see Figure 1). The current management involves dredging up to $40,000 \mathrm{~m}^{3}$ of sand per year from the lower reaches of the estuary and depositing it on Burleigh Beach to the north of the adjoining headland.

Any long-term solution for the management of the creek entrance sedimentation issue requires an understanding of the hydrodynamic behaviour of the creek. Ultimately decision makers will benefit from being able to predict the potential impacts upon the creek morphology for alternatives to the current dredging regime for a range of physical conditions. The first stage of this process is the development of a hydrodynamic model of Tallebudgera Creek to gain improved understanding of the morphological behaviour of the creek.

Several physical parameters such as the tide, the coastal wave climate, the sediment volume and actual morphology, may contribute to the evolution of the sand bars, particularly in the lower estuarine area. Therefore, the numerical model has to consider these parameters as accurately as possible for an optimal simulation of the morphological evolution.

The basis for the hydrodynamic model is DELFT3D which is widely used for simulating the effect of waves, hydrodynamics and sediment transport applied to marine and coastal engineering.

\section{METHODOLOGY}

\subsection{Computational Grid}

A computational grid was constructed for the model area using a digitised shoreline for the creek and hydrographic surveys obtained from Gold Coast City Council. Figure 2 (left) displays an example of the computational grid and bathymetry for one the largest meanders in the lower reach of the creek. The 
computational grid is curvilinear with quadrilateral grid cells. The grid has to respect orthogonality and smoothness for convergence of the numerical model and to obtain accurate solutions. Inside the creek, the order of magnitude of a grid cell varies from 1 to $10 \mathrm{~m}$. The choice of computational grid resolution considers the creek dimensions and is a compromise between output precision and simulation time.

\subsection{Bathymetry}

Defining the depth of the model domain is critical and requires assigning a depth value to every computational grid cell node. Depth samples from hydrographic survey data are laid over the grid and averaged or interpolated to define depths at the grid points resulting in the initial model bathymetry. An example of the initial model bathymetry is shown in Figure 2 (left) where blue represents deep water, yellow is shallow water and green areas are exposed at low tide.

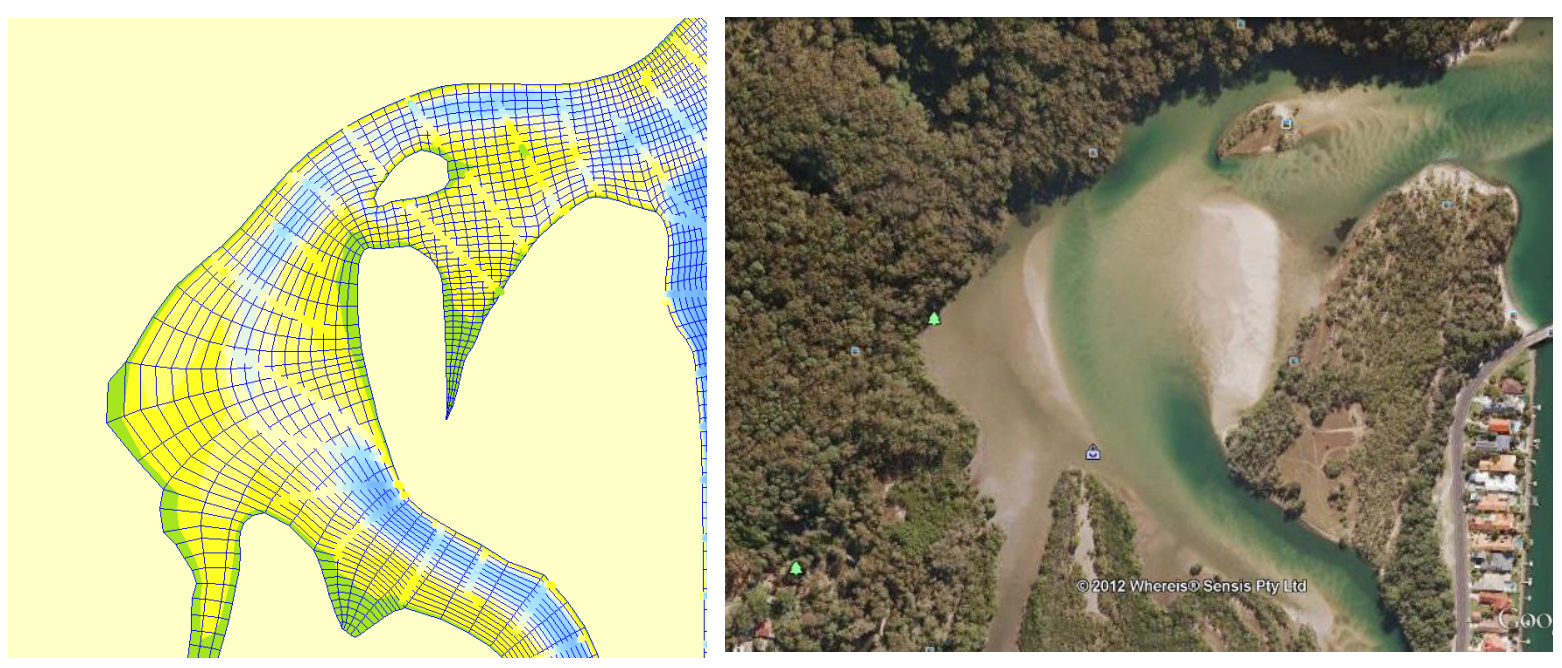

Figure 2. Computational grid and bathymetry (left), aerial photograph of model area (right)

The construction of the model bathymetry (Figure 2, left) was problematic due to the low density of survey samples in some areas and required some estimation of poorly sampled shallow areas, in particular, from visual inspection of aerial photographs (e.g. Figure 2, right).

Some specific limitations on the development of an accurate bathymetry include the following:-

- the most detailed available hydrographic survey of Tallebudgera Creek was conducted in September 2006, more than 7 years ago. Since then there may have been natural (e.g. high rainfall) and artificial (e.g. dredging) events which could have impacted the creek morphology.

- the satellite image, Figure 2 from Google Earth, used in order to check the bathymetry and to make some corrections was dated June 23, 2010. This constitutes a significant temporal gap with the year of the bathymetric survey and these visual estimations were unable to be validated.

- the creek had been surveyed by cross-sections at intervals of approximately one hundred metres, and up to three hundred metres in some locations. This means that over areas of one hundred metres, and sometimes further, there is no information about the creek bathymetry. Therefore, small rocky outcrops, sand bars and other morphological features which may affect the hydrodynamics are likely to have been omitted in some areas within the model of the creek.

\subsection{Physical and numerical structure}

The hydrodynamic model presented in this paper does not yet consider the impact of oceanic waves, wind or sediment transport. Only the forcing due to tidal water level variations and discharge from the catchment are taken into account here and the model is calibrated using specific model parameters such as bed roughness. Thus this is considered as the first stage of the model and is the first calibration for the development of future more complex models which will incorporate the additional inputs above. Several simulations have been conducted to test the sensitivity of input parameters. 


\subsection{Environmental data}

As the model is expected to simulate reality it has to represent the physical environment so field data is required for the calibration. There are a two main physical phenomena for which data has been collected at specific locations within the creek system: the total discharge has been collected $10 \mathrm{~km}$ upstream from the entrance at the Tallebudgera Connection Road bridge; and the water level is represented at the model boundary (the offshore tide) (DHI, 2011). The tidal measurements were obtained from a pressure gauge deployed approximately $500 \mathrm{~m}$ east of the Palm Beach shoreline and $2 \mathrm{~km}$ south of the entrance to Tallebudgera Creek at $7 \mathrm{~m}$ water depth. A slight phase lag (not known precisely) may exist however this has not been taken into account. There is not considered to be any impact on tidal amplitude between the offshore boundary of the model and the location of the pressure gauge.

\subsection{Model Calibration}

The model was run from 0000 on April 19, to 1200 on April 20, 2011, coinciding with the available data. At the start of the simulation the creek discharge was slightly above average, ranging from almost $1.5 \mathrm{~m}^{3} \mathrm{~s}^{-1}$ at the start of the simulation and decreasing to $1 \mathrm{~m}^{3} \mathrm{~s}^{-1}$ at the end. The simulation duration of 36 hours used a time step of $\mathrm{dt}=0.01 \mathrm{~min}$ which required at least 8 hours of run time on a standard desktop PC. The time step was chosen small enough to resolve the highest resolution grid cells without requiring excessive computational time for convergence.

An important model parameter for calibration is the hydrodynamic bed roughness. Physically, hydrodynamic roughness corresponds to the amount of frictional resistance that a fluid experiences when passing over the topographic and morphological features of the creek. The roughness was specified using the Manning coefficient, $\mathrm{n}$. An increase in $\mathrm{n}$ represents increasing bed roughness and will cause a decrease in the velocity of water flowing across a surface. Moreover, it is expected that a tidal phase lag will be progressively observed upstream.

The empirical equation below, the Manning's equation, shows how the dimensionless $\mathrm{n}$ value, might be estimated locally:

$$
\bar{V}=\frac{1}{n} R^{\frac{2}{3}} S^{\frac{1}{2}}
$$

where $\bar{V}\left(\mathrm{~ms}^{-1}\right)$ is the mean velocity of flow, $\mathrm{R}(\mathrm{m})$ the hydraulic radius and $\mathrm{S}$ (dimension-less) the channel gradient. For the lower reach of Tallebudgera Creek the creek bed remains relatively constant compared to the mean sea level, i.e. $\mathrm{S} \sim 0$, thus it is difficult to determine a mean flow velocity and a value for $\mathrm{n}$, via the empirical Manning formula.

An alternative method for selecting an appropriate roughness value was considered. Roughness is directly controlled by the grain size of the creek bed and bank material, the amount of channel vegetation and the irregularity of the adjacent channel cross-section. The Tallebudgera Creek bed generally consists of fine sand with small areas of sea grass and some rocky outcrops. Some sand bars of variable sizes are exposed at lower water levels which are partly vegetated.

Literature (e.g. Nielsen, 1992; Chorley et al., 1984) suggests a general parameter range within which the roughness of Tallebudgera Creek must be encompassed; although this is based on empirical and subjective observations. Values within the range of $0.015<\mathrm{n}<0.045$ were therefore proposed to be tested for the lower Tallebudgera Creek. For this study two simulations were executed with two different (but spatially constant) values of the Manning coefficient: $n=0.02$ and $n=0.04$.

\subsection{Model Validation}

As field measurements from Tallebudgera Creek were scarce, the model validation presented here is mainly based on the comparison of the observed and modelled water levels. Water level measurements were collected at two locations on Tallebudgera Creek in April 2011 near Tallebudgera Connection Road Bridge at the upstream end of the model area (Tallebudgera upstream), and at the Gold Coast Highway Bridge which is located at 700 metres from the creek entrance (Tallebudgera downstream). The water levels were measured as heights in metres above the Australian Height Datum (AHD) which is very close to mean sea level in this region. 


\section{RESULTS AND ANALYSIS}

\subsection{Roughness sensitivity}

Two different values of the Manning coefficient $\mathrm{n}$ were implemented as discussed above. Figure 3 displays the simulated upstream water level as a function of time for $n=0.02$ (green) and $n=0.04$ (red) compared to the measured data (blue). Note that the blue line (measured data) displays an unusual low tide curve such that a local minimum water level is obtained for the upstream location which will be discussed later.

With respect to the modelled tidal amplitude and phase there are three key findings:

- The results of the simulation with Manning coefficient $n=0.04$ (red curve) and the observed data (blue curve) show a good agreement in phase but with slightly different water levels. The modelled water level is about $0.15 \mathrm{~m}$ below the observed water level with the exception of the low tide periods.

- The simulation result for Manning coefficient $n=0.02$ (green curve) shows a positive phase shift relative to the two other curves. Its amplitude is slightly more than the previous simulation where $n=0.04$ (red curve), but water levels are generally lower than the observed data.

- Neither the red curve nor the green curve replicated the restriction in the observed low tide data.

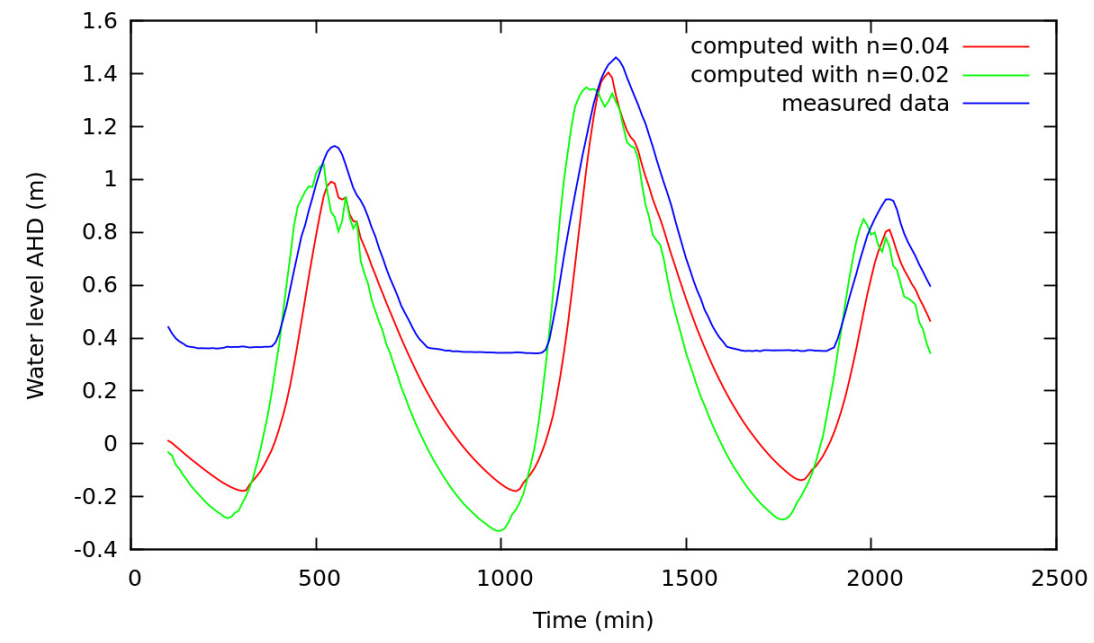

Figure 3. Modelled and observed water level, Tallebudgera Upstream.

With respect to the observations of the model results for the downstream location (Figure 4) the following are noted:

- The computation using $\mathrm{n}=0.02$ (green curve) shows very good agreement with the physical measurements. - The simulation using $n=0.04$ (red curve) shows only a small amplitude decrease and a slight phase lag

The results are quite good overall considering the complex bathymetry and availability of accurate survey data. There is a general agreement with the observed data for the downstream site and for mid- to high water at the upstream site.

The choice of $\mathrm{n}=0.04$ resulted in better agreement with data at the upstream location while $\mathrm{n}=0.02$ gave better results at the downstream location. Clearly a creek is unlikely to be constrained to a constant roughness over its entire length and is likely to possess spatial variability. Nevertheless, it appears that the choice of values of $n=0.04$ and $n=0.02$ provide a suitable approximation for the reaches of Tallebudgera creek modelled in this study. Moreover, it is suggested that $n=0.04$ is a more applicable value for the upper part of the study area and $n=0.02$ is a better choice for the lower reach and estuary.

Bed roughness creates resistance to the fluid flow and therefore has two main impacts on the tidal flow of the creek. A high roughness value will act to reduce tidal amplitude and increase the tidal phase lag upstream. The results above suggest that the upper reach of the creek bed is likely to have an increased bed roughness. 


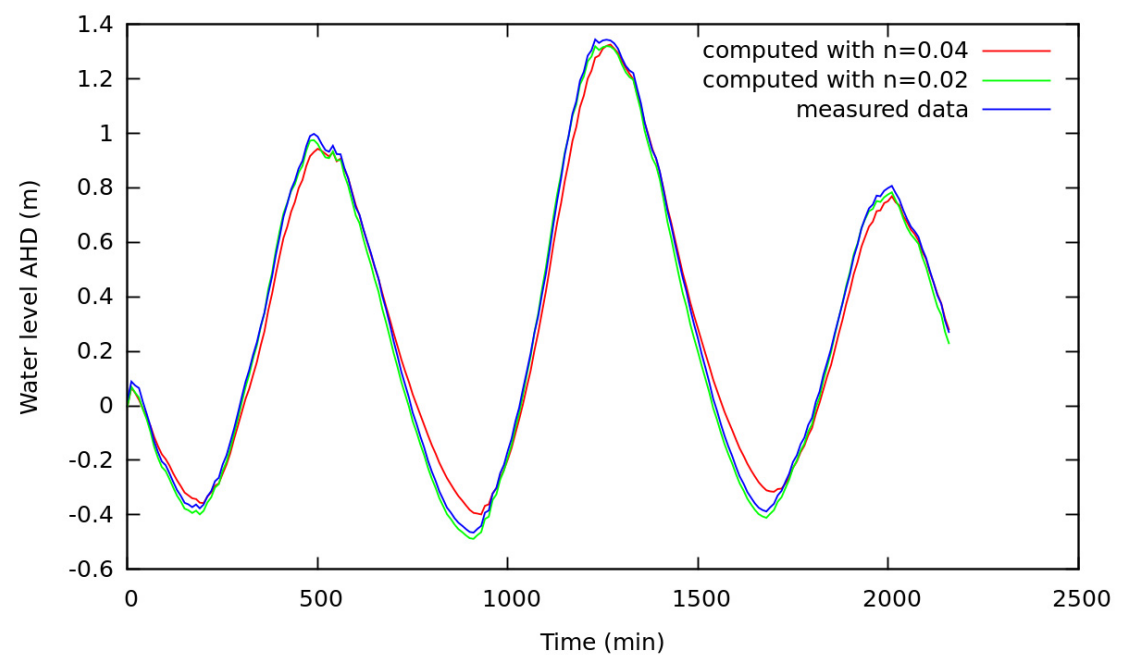

Figure 4. Modelled and observed water level, Tallebudgera Downstream.

Further investigation of the observed restricted low water levels upstream was conducted in conjunction with site visits, anecdotal evidence and observations from aerial photographs to find potential explanations for the unusual low tide water levels. It became evident that there are sections of the creek where some shallow rocky outcrops extend across the creek. At least one outcrop section covers the entire width of the creek and consequently prevents the water level falling below approximately $0.3 \mathrm{~m}$ AHD during days of low discharge (below $0.7 \mathrm{~m}^{3} \mathrm{~s}^{-1}$ ). During the period of the study the minimum upstream water level observed at low tide was approximately $0.4 \mathrm{~m}$ AHD while the discharge exceeded $1 \mathrm{~m}^{3} \mathrm{~s}^{-1}$.

Following these observations, two shallow regions were added to the bathymetry at the upstream end of the model and a sand bar which was already partially represented in the bathymetry of the lower reach was raised and widened slightly. Figure 5 (left) displays the revised bathymetry of the rocky obstructions observed in the upper reach of the creek.

In addition to incorporating more detail for critical model areas a variable roughness was applied by defining distinct reaches of the creek with similar bed characteristics. Three large areas were identified and a constant bed roughness applied in each. The first area includes the lower reach and whole estuarine zone including the ebb and flood tidal deltas. This wide reach mainly consists of sand bars interspersed with deeper areas. The roughness for the lower reach was set to $n=0.03$ (Figure 5, second from left). The mid-section contains two artificial canals connected perpendicularly to the creek, the roughness for this region was set lower to $\mathrm{n}=$ 0.02 (Figure5, third from left). The third region is upstream reach of the creek which is narrow and meandering with sea grass areas, shallow, partly vegetated sand banks with trees on the creek banks. Here, the roughness was set higher with $n=0.04$ (Figure 5, right).
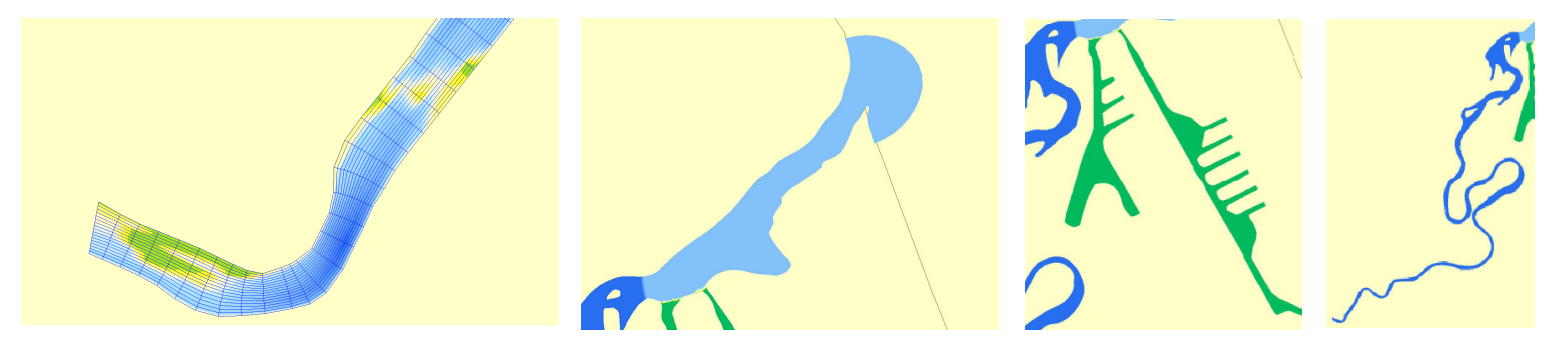

Figure 5. From $\mathrm{L}$ to R; revised bathymetry region, variable roughness of lower reach $(\mathrm{n}=0.3)$, middle reach $(\mathrm{n}=0.2)$ and upper reach $(\mathrm{n}=0.4)$

The modelled water level has improved remarkably following the inclusion of the additional obstructions in the bathymetry and the three separate roughness areas (Figure 6). The modelled water level no longer falls below $0.35 \mathrm{~m}$ AHD at low tide and compares well with the measured water level throughout. As discussed previously these final simplistic roughness parameter specifications were guided by sensitivity testing and literature (Arcement and Schneider, 1989; Limerinos, 1970) which attempt to link, as rigorously as possible, Manning's roughness coefficient $\mathrm{n}$ with all the physical and vegetative features specific to a channel or a well-defined river bed. 


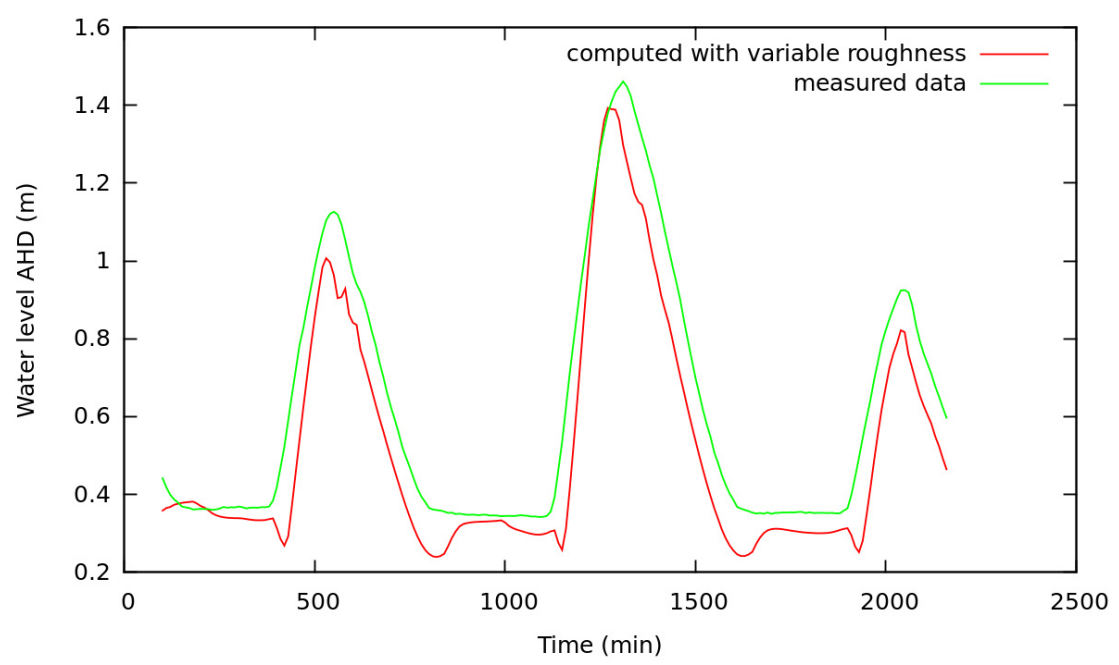

Figure 6. Variable roughness modelled water level and measured water level, Tallebudgera Upstream

At the downstream site the two curves are almost completely superimposed (not shown here). At the upstream site the two curves closely follow the same pattern with respect to their amplitude and phase and the model now represents the local minimum water level during the low tides quite well (Figure 6). The modelled values of water level are still a little lower than those measured by about $0.1 \mathrm{~m}$.

\section{CONCLUSIONS}

This paper presents the results of the development and calibration of a hydrodynamic model of a small coastal creek in Southeast Queensland, Australia. The primary use of such a model is to describe the tidal flow behaviour for a complex hydrodynamic system and thus infer the motion of water at a given location and at a given time. From this point, other possible outcomes arise and enable the extension of the hydrodynamic model to include coastal waves and sediment transport processes. In the case of Tallebudgera Creek, it ultimately leads to simulation of dredging and infilling scenarios and thus can be extended to test the potential impacts of future management strategies. Good results were obtained from the model with some relatively crude parameterisations of the physical processes over a short time. The study also emphasised the importance of capturing significant structural components of the creek morphology during surveying for the most accurate model results.

\section{ACKNOWLEDGEMENTS}

The data used in this study was provided by the Gold Coast City Council.

\section{REFERENCES}

Arcement, G.J., Jr. and Schneider, V.R. (1989). Guide for selecting Manning's roughness coefficient for natural channels and flood plains. Water-supply Paper 2339 / United States Geological Survey.

Chorley, R. J., Schumm, S.A. and Sugden, D.E. (1984). Geomorphology, Metheun \& Co. London.

DHI (2011). GCSMP - Field Measurements \& Data Collection. DHI Water and Environment Technical Report. June 2011.

Limerinos, J. T. (1970). Determination of the manning coefficient from measured bed roughness in natural channels. Water-supply Paper 1898-B / United States Geological Survey.

MSQ (2013). Online Tide Tables - 2013. The State of Queensland (Department of Transport and Main Roads) 2010-2013. Queensland Government. http://www.msq.qld.gov.au/Tides/Tide-tables-2013.aspx Accessed 25th September 2013. Produced by National Tidal Centre, Bureau of Meteorology, Australia. Nielsen, P. (1992). Coastal Bottom Boundary Layers and Sediment Transport. Volume 4. World Scientific. 